\title{
Emotion
}

\section{Effects of Intranasal Oxytocin on 'Compassion Focused Imagery'}

Helen Rockliff, Anke Karl, Kirsten McEwan, Jean Gilbert, Marcela Matos, and Paul Gilbert Online First Publication, June 27, 2011. doi: 10.1037/a0023861

CITATION

Rockliff, H., Karl, A., McEwan, K., Gilbert, J., Matos, M., \& Gilbert, P. (2011, June 27). Effects of Intranasal Oxytocin on 'Compassion Focused Imagery'. Emotion. Advance online publication. doi: 10.1037/a0023861 


\title{
Effects of Intranasal Oxytocin on 'Compassion Focused Imagery'
}

\author{
Helen Rockliff \\ University of Bristol
}

\author{
Kirsten McEwan and Jean Gilbert \\ University of Derby
}

\author{
Anke Karl \\ University of Exeter \\ Marcela Matos \\ University of Coimbra
}

\author{
Paul Gilbert \\ University of Derby
}

\begin{abstract}
This study explored the effects of oxytocin on Compassion Focused Imagery (CFI), that is, imagining another "mind" being deeply compassionate to oneself, and the interaction of these effects with self-criticism and feeling socially safe with others. Forty-four healthy participants (29 men and 15 women) completed self-report measures of self-criticism, attachment style, and social safeness before taking part in a double-blind randomized placebo controlled study. They attended two imagery sessions, receiving oxytocin in one and a placebo in the other. Positive affect was measured before and after each imagery session, and "imagery experience" was assessed after each session. Overall, oxytocin increased the ease of imagining compassionate qualities but there were important individual differences in how CFI was experienced. Participants higher in self-criticism, lower in self-reassurance, social safeness, and attachment security had less positive experiences of CFI under oxytocin than placebo, indicating that the effects of oxytocin on affiliation may depend on attachment and self-evaluative styles.
\end{abstract}

Keywords: attachment, compassion, imagery, oxytocin, positive affect, self-criticism

The evolution of mammalian caring behavior has been at the root of some of the most significant adaptations for social behavior, empathy, mentalizing, and affect regulation (Bowlby, 1969, 1973; Cozolino, 2007; Mikulincer \& Shaver, 2007). Children from secure and loving backgrounds develop enhanced motivation and competencies for empathy and compassion for self and others, in comparison with children from insecure backgrounds (Gillath,

Helen Rockliff, Henry Wellcome Laboratories for Integrative Neuroscience and Endocrinology, University of Bristol, Bristol, United Kingdom; Anke Karl, School of Psychology, University of Exeter, Exeter, United Kingdom; Kirsten McEwan, Jean Gilbert, and Paul Gilbert, University of Derby, Mental Health Research Unit, Derby, United Kingdom; Marcela Matos, Cognitive-Behavioural Research Centre, University of Coimbra, Portugal.

We thank Professor Markus Heinrichs, University of Freiburg, Germany for helpful guidance on methodological aspects of the study and Dr. David Baldwin, University of Southampton, United Kingdom, for on-site medical support of our study. We also thank Beth Curl for her help with guided imagery recording and data entry and Proctor and Gamble for donating pregnancy tests. This research was funded by the Compassionate Mind Foundation. The authors reported no biomedical financial interest or potential conflicts of interest. Professor Paul Gilbert is the founding president of the charity The Compassionate Mind Foundation which funded this study. Supplementary material cited in this article is available online at www.compassionatemind.co.uk.

Correspondence concerning this article should be addressed to Paul Gilbert, Mental Health Research Unit, Kingsway House, Kingsway Hospital, Derby DE22 3LZ, United Kingdom. E-mail: p.gilbert@derby.ac.uk
Shaver, \& Mikulincer, 2005). Outside the infant-parent bond, feeling cared for by one's partner, friends, teachers, or employers has a fundamental impact on regulating physiological and emotional states (Cacioppo, Berston, Sheridan, \& McClintock, 2000). Feeling that one is the recipient of care and support from others creates a feeling of safeness and soothing linked to well-being, whereas feeling uncared for is linked to mental and physical health problems (Cozolino, 2007, 2008). The degree to which people feel secure and wanted in their current relationships is positively associated with positive affect and negatively associated with cyclothymic and dysthymic temperament in both student and bipolar disorder groups (Gilbert et al., 2008).

The evolution of caring requires that individuals can approach and interact with each other without activating the fight-flight system (Porges, 2007). Along with modifications to the peripheral nervous systems, a range of central nervous system adaptations, including neuropeptides, have played a role in the development of affiliative motivations, competencies, and behaviors (Bell, 2001; Insel, 1997; MacDonald \& MacDonald, 2010; Panksepp, 1998).

The neuropeptide oxytocin has been found to influence a range of affiliative behaviors (Meyer-Lindenberg, 2008) including trust (Baumgartner, Heinrichs, Volanthen, Fischbacher, \& Fehr, 2008; Kosfeld, Heinrichs, Zak, Fischbacher, \& Fehr, 2005; Theodoridou, Rowe, Penton-Voak, \& Rogers, 2009), social cognition and empathy (Bartz et al., 2010a), social memory (Rimmele, Hediger, Heinrichs, \& Klaver, 2009; Savaskan, Ehrhardt, Schulz, Walter, \& Schachinger, 2008), and interpretation of facial expressions (Domes, Heinrichs, Michel, Berger, \& Herpertz, 2007b; Guastella et al., 2009a). It also increases attentional bias for rewarding social 
cues (Guastella, Mitchell, \& Mathews, 2008) and has been found to enhance the attenuation of stress responses by social support (Heinrichs, Baumgartner, Kirschbaum, \& Ehlert, 2003). Indeed, Carter (1998) and Depue and Morrone-Strupinsky (2005) suggest that oxytocin plays an important role in suppressing threat responses, facilitating closeness and attachment bonds, and increasing motivations to engage in caring behaviors. One way it may do this is via modulation of amygdala responses to social emotions (Domes et al., 2007a; Kirsch et al., 2005; Petrovic, Kalisch, Singer, \& Dolan, 2008).

It is therefore reasonable to suppose that oxytocin might provide an important adjunct to therapeutic interventions especially for those who struggle with affiliative behavior and emotion and can be wary of reassurance and compassion from others (Gilbert \& Irons, 2005; Gilbert, McEwan, Matos \& Rivis, in press). Indeed, exploration of the therapeutic benefits of oxytocin for various psychological conditions has begun and results have thus far been promising (Guastella, Howards, Dadds, Mitchell, \& Carson, 2009b; Hollander et al., 2007; Hollander et al., 2003). In addition, Buchheim et al. (2009) found that when they gave oxytocin to insecurely attached men, the majority experienced an increase in attachment security.

Recently there has been a new focus for psychotherapy on developing patients' capacity for self-compassion and openness to the compassion of others (Gilbert, 2000, 2010). Compassion involves a motivation to care and feelings of warmth, understanding, and kindness toward oneself and others (Goetz, Keltner, \& SimonThomas, 2010). One way in which compassion and affiliative capacity might be built is through practicing Compassion Focused Imagery (CFI).

Imagery plays an important role in therapeutic interventions (e.g., Arbuthnott, Arbuthnott, \& Rossiter, 2001; Hall, Hall, Stradling, \& Young, 2006; Holmes \& Mathews, 2010; Stopa, 2009) and has been used to desensitize individuals to feared stimuli and more recently to stimulate positive emotions associated with "success and coping" and "affiliation and compassion" (Stopa, 2009). As part of a therapy, CFI, where one imagines another mind having compassionate feelings, motivations, and thoughts directed to oneself, has been shown to reduce self-criticism and psychopathology and increase feelings of self-compassion and selfreassurance in a number of mental health settings (Gilbert \& Procter, 2006; Laithwaite et al., 2009; Kelly, Zuroff, \& Shapira, 2008; Mayhew \& Gilbert, 2008; Mongrain, Chin, \& Shapira, in press). Similarly, practicing Loving Kindness Meditation (LKM) (where one directs loving/friendly feelings toward oneself and others) has been shown to increase positive emotions, mindfulness, feelings of purpose in life, and perceived social support and decrease illness symptoms in students (Fredrickson, Cohn, Coffey, Pek, \& Finkel, 2008).

\section{Individual Differences}

There are important individual differences in how people experience compassion and affiliation, which may have implications for the effects of oxytocin on affiliative behavior. For example, individuals with psychological difficulties, who come from backgrounds with little warmth or caring, can find it very difficult to be open to caring from others or to be self-compassionate (Gilbert \& Irons, 2005; Gilbert et al., in press). These individuals are typically very self-critical (Gilbert, McEwan, Bellew, Mills \& Gale, 2009; Luyten et al., 2006; Whelton \& Greenberg, 2005; Zuroff, 1992), and even imagining compassion from others or self-compassion can be difficult or frightening (Gilbert \& Procter, 2006). Indeed, decreases in Heart Rate Variability (HRV) and lack of significant reduction in cortisol, in response to CFI, have been associated with higher levels of self-criticism (Rockliff, Gilbert, McEwan, Lightman, \& Glover, 2008). Similarly Longe et al., (2010) found that when engaged in self-critical thinking, the degree of activation in the dorsal lateral prefrontal cortex (DLPFC) (an area of the brain associated with error detection and inhibition of socially inappropriate behavior) was related to self-criticism. When engaged in self-reassuring thinking, self-criticism was associated with increased activation of the amygdala, consistent with reports that efforts to be self-reassuring can be difficult or feel threatening.

Individual variation in how people respond to oxytocin has also been associated with attachment style. Bartz et al. (2010b) explored the recall of maternal caring behavior. They found that after oxytocin, less anxiously attached men recalled their mothers as more caring but more anxiously attached men remembered their mothers as less caring. Similarly, data from Rockliff et al. (2008) found that anxious attachment was associated with physiological indicators of a threat response to CFI whereas for more securely attached participants this was associated with physiological changes indicative of a calm emotional state. Such findings indicate the importance of studying individual differences, in particular the possibility that for some individuals, affiliative emotions are experienced as threatening.

At present it is unknown whether oxytocin influences the experience of receiving care/compassion within CFI. However, one could hypothesize that because both oxytocin and compassion may stimulate affiliative systems, there may be additive effects of oxytocin which result in facilitation of CFI. Hence, given the growing interest in compassion and oxytocin as therapeutic agents, and the potential importance of individual differences in experiencing affiliative emotion, this study aimed to explore the effects of oxytocin on the experience of CFI.

\begin{abstract}
Aims
The aim of this study was to investigate whether oxytocin (in comparison with placebo) enhances the ease with which people can create CFI and the quality of the emotional experiences associated with it. We hypothesize that oxytocin will be associated with greater ease of imagining compassion and with reduced feelings of resistance to the affiliative emotional content of the imagery. However, we also expect there may be individual differences in the effects of oxytocin on compassionate imagery, and that these will be related to psychological traits of attachment, self-criticism, and social safeness.
\end{abstract}

\section{Method}

\section{Participants}

Participants were recruited via email and poster advertisements at the University of Southampton. We screened 241 respondents to ensure a healthy, nonsmoking, medication-free population (including use of hormonal contraception), with no history of serious 
psychiatric illness or previous participation in oxytocin research, and who were not currently pregnant or breastfeeding. Of these, 44 participants completed the study. However, data from three participants were removed for sleeping and coughing excessively during the CFI, leaving a final sample of 41 participants (26 men, 15 women; mean age $=26.03, S D=8.53$ years).

\section{Procedure}

All participants completed self-report measures of self-criticism and self-reassurance (Gilbert, Clarke, Hempel, Miles, \& Irons, 2004), attachment style (Collins \& Read, 1990), and social safeness and pleasure (Gilbert et al., 2009) before attending the compassionate imagery sessions. They were then invited to attend two 1-hr sessions at Southampton University (Sessions A \& B), approximately 10 days apart (mean no. days $=10.65, S D=10.28$ ). Before each session, all participants were asked to refrain from consuming alcohol for 24 hours, caffeine for 5 hours, and food for 2 hours. Using a within-subjects counterbalanced and doubleblinded design, participants were randomized to receive either an oxytocin or a placebo nasal spray in Session A, and the other spray type in Session B. All menstrual females $(n=12)$ participated in both sessions during their luteal phase. Three females were postmenopausal.

All sessions were conducted between 2 p.m. and 7 p.m. and followed identical protocols: Participants signed consent forms, then, observed by the researcher, they self-administered a nasal spray containing 24IU oxytocin or a placebo (Victoria Pharmacy, Zurich). Before and after each session of CFI participants completed the Positive and Negative Affect Schedule (PANAS) (Watson, Clark, \& Tellegen, 1988) but with the instructions to focus on how they were feeling "right now." They also completed the Types of Positive Affect Scale (TPAS) (measuring activated e.g., feeling excited, relaxed e.g., feeling calm, and Safe/content e.g., feeling secure, positive affects) but with the instruction changed to focus on feelings "right now" (Gilbert et al., 2008). Next, participants were shown 30 minutes of a neutral nature documentary to optimize timing of the peak effects of the nasal spray with the CFI (Heinrichs et al., 2003). After the documentary, participants listened to a recorded outline of the imagery task, a definition of compassion, an explanation of what was meant by "mental imagery," and advice on how to deal with one's mind wandering (i.e., not to worry, but simply guide it back to the imagery). The recording was paused at this point to allow for possible questions or clarification of the task, before continuing with a five-minute relaxation and seven minutes of guided CFI.

The relaxation involved practicing a soothing rhythm of breathing and imagining tension draining from ones muscles. The CFI involved participants generating visual images of a deeply compassionate person/being. They were asked to imagine being the recipient of compassion and feelings of warmth, understanding, and care, emanating from this image to them. The researcher guided each participant through the CFI, with verbal prompts at 45-second intervals, focusing on compassionate qualities (e.g., "focus on the wisdom and understanding that is there for you; imagine being understood and completely accepted; focus on the great warmth and kindness that permeates the whole image and is directed at you"). Transcripts and instructions of the imagery are available from the authors.
After the CFI, participants answered a series of questions regarding their experiences of CFI. Seven questions asked participants to rate on a 1-10 Likert scale: their ease of imagery, resistance to emotions, and clarity of imagery. Question 8 asked about the ease of imagining compassionate qualities from the image (e.g., wisdom, kindness, warmth). Question 8 items were summed to give an overall score of ease of feeling these compassionate qualities. Questions 9 and 10 invited participants to write about their experiences of CFI and were used for qualitative content analysis of themes. The questions are given in Appendix 1.

After the CFI, participants completed the PANAS and TPAS a second time, thus providing pre and post data on mood. Participants were then debriefed by the researcher about the study hypotheses after they had completed both Sessions A and B. All participants received $£ 18$ or 12 course credits.

\section{Data Analysis}

All quantitative data were analyzed using SPSS (version 18; ${ }^{\circ}$ 2010 SPSS Inc.). Data were analyzed for normality of distribution using skewness, kurtosis, scatter-plots, and histograms. These analyses showed that the variables were normally distributed except the negative affect subscale of the PANAS, which was highly skewed and kurtotic showing floor effects. When nonparametric tests were conducted for this variable, there were no significant findings. For these reasons we will not report the data for negative affect. Participants were asked which spray they thought they had at each session. Participants' guesses were not significantly above chance levels, thus they were in general not able to guess accurately which spray they had taken.

To explore whether condition order (i.e., whether they took oxytocin or placebo first) had any effect on CFI experience, we conducted a series of mixed measures ANOVAs with spray condition as a within-subjects factor and condition order as betweensubjects factor. Results revealed a significant interaction $[F(1$, $39)=6.75, p=.013$ ] for 'resistance of compassionate emotions' (question 2, see Appendix 1). A post hoc $t$ test revealed this effect was significant in the oxytocin condition $[t(39)=3.15, p=.004]$ such that, those given oxytocin first felt more resistance to compassionate emotions (question 2) than those given placebo first. Various explanations are possible, such that placebo is a gentler introduction to compassion, but this would require further research. Interestingly, if the samples are split according to high and low criticism score, these significant effects are only present for high self-critics who show significantly more resistance to CFI when given oxytocin first $[F(1,20)=8.00, p=.010] ;[t(20)=$ 3.22, $p=.004]$.

\section{Results}

\section{Effects of Oxytocin on the CFI Experience}

To investigate whether the CFI was experienced differently in the oxytocin and placebo conditions, a series of repeated measures ANOVAs with spray condition as a within-subjects factor were performed. A significant main effect was found in the oxytocin condition for the summed score of all compassionate qualities (question 8, see Appendix 1) $[F(1,40)=18.92, p<.001]$, indicating that oxytocin significantly enhanced the ease of imag- 
ining the compassionate qualities (e.g., wisdom, strength, kindness). There were no significant main effects for questions 1-7 (e.g., ease of imagery, resistance to emotions and clarity of image).

\section{Effects of Oxytocin on Mood After CFI}

Participants completed the TPAS (measuring activated, relaxed, and safe/content positive affects) and the PANAS before and after CFI. To investigate whether more positive emotions were reported in the oxytocin or placebo condition, a series of repeated measures ANOVAs with spray condition and positive affect before/after CFI as within-subjects factors were performed.

There was a significant main effect of spray condition, with a greater decrease in positive affect (PANAS) (i.e., a measure of mainly activated positive affect such as excitement), and a greater increase in relaxed positive affect (TPAS) in the placebo condition compared with the oxytocin condition (see Table 1). There were also significant main effects for activated and relaxed positive affects (TPAS) before/after CFI. In both spray conditions there was a significant decrease in activated positive affect and a significant increase in relaxed positive affect. No significant interactions between before/after and spray condition were observed.

\section{Role of Individual Differences in Response to CFI and Oxytocin}

We conducted mixed measures ANOVAs and post hoc $t$ tests (independent-samples $t$ tests to explore group differences and paired-samples $t$ tests to explore spray condition effects) to explore the role of individual differences (such as self-criticism, attachment, and social safeness) on experiences of CFI. Median scores were used to split the sample into groups according to high and low scores on the self-criticism/reassurance scale (as measured by the subscales inadequate self and self-reassurance), attachment scale variables (close, depend and anxious), and social safeness. The high and low groups were used as between-subjects factors with spray condition as a within-subjects factor.

\section{Self-Criticism and Self-Reassurance}

Self-criticism. A significant interaction was found between level of self-criticism and spray condition $[F(1,39)=4.40, p=$ .043] for 'resistance to compassionate emotions' (question 2) (see Figure 1A). Post hoc $t$ tests revealed that in the oxytocin condition, individuals with high levels of self-criticism showed nonsignificant trends for greater resistance toward the compassionate emotions than during the placebo condition $[t(21)=-2.00, p=.059]$ and compared with those with low levels of self-criticism $[t(39)=$

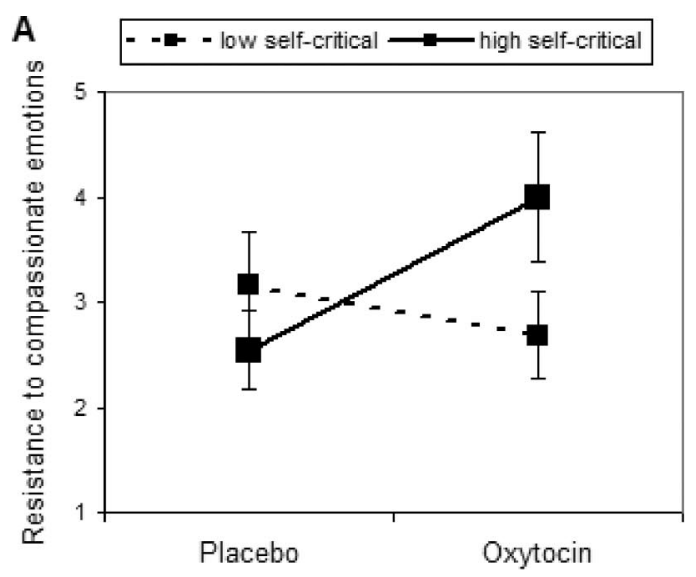

$\mathbf{B}$

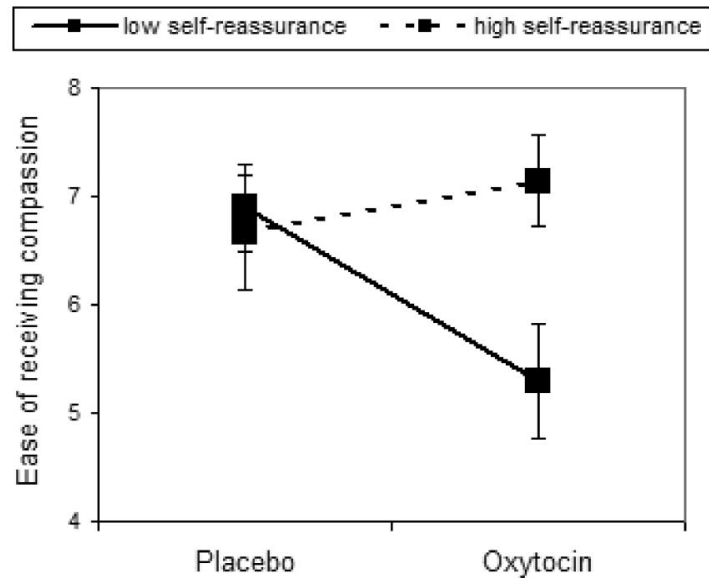

Figure 1. A, Interaction between spray condition and self-criticism for self-reported resistance toward compassionate emotions. B, Interaction between spray condition and self-reassurance for self-reported ease of receiving compassionate emotions.

$1.77, p=.085]$. These effects were reflected in the qualitative descriptions (question 10) of the experience, with high self-critics reporting more negative experiences of CFI with oxytocin. There were no additional significant effects for the other questions regarding experience of CFI.

Self-reassurance. Significant interactions were found between level of self-reassurance and spray condition for the 'ease of receiving compassion' (question 1$)[F(1,39)=7.17, p=.011]$

Table 1

Means, SD, and ANOVA Results for Mood Before and After CFI

\begin{tabular}{|c|c|c|c|c|c|c|}
\hline & \multicolumn{2}{|c|}{ Oxytocin } & \multicolumn{2}{|c|}{ Placebo } & \multirow{2}{*}{$\begin{array}{l}\text { ANOVA main effect } \\
\text { Oxytocin/placebo }\end{array}$} & \multirow{2}{*}{$\begin{array}{l}\text { ANOVA main effect } \\
\text { Before/after }\end{array}$} \\
\hline & Before & After & Before & After & & \\
\hline Activated & $15.86(5.45)$ & $9.41(6.21)$ & $14.81(6.19)$ & $8.22(6.85)$ & $F(1,39)=3.01 ; p=.090$ & $F(1,39)=95.99 ; p<.001$ \\
\hline Relaxed & $13.05(3.94)$ & $15.67(5.17)$ & $13.61(3.32)$ & $17.27(2.83)$ & $F(1,39)=4.67 ; p=.037$ & $F(1,39)=32.33 ; p<.001$ \\
\hline Safe/content & $10.21(2.80)$ & $9.54(2.58)$ & $10.44(2.14)$ & $10.44(2.05)$ & $F(1,39)=2.42 ;$ n.s. & $F(1,39)=1.17 ;$ n.s. \\
\hline Positive affect (PANAS) & $28.43(6.87)$ & $26.13(7.52)$ & $28.05(6.82)$ & $25.25(7.45)$ & $F(1,39)=11.87 ; p<.001$ & $F(1,39)=0.73$; n.s. \\
\hline
\end{tabular}


(see Figure 1B) and being "emotionally moved" by the CFI (question 6) $[F(1,39)=6.74, p=.013]$. Post hoc tests revealed that in the oxytocin condition, individuals with low levels of selfreassurance found it significantly more difficult to receive compassionate emotions than in the placebo condition $[t(19)=2.79$, $p=.012]$ compared to high self-reassuring individuals $[t(39)=$ $2.74, p=.009]$. Furthermore, those with higher levels of selfreassurance showed a nonsignificant trend to have felt more moved in the oxytocin compared to the placebo condition $[t(20)=$ 2.02, $p=.056$ ] and showed a nonsignificant trend to feel more moved compared to individuals with low levels of self-reassurance $[t(39)=-1.87, p=.070]$. With regard to changes in positive affect in response to CFI, a significant interaction was found between level of self-reassurance, spray condition, and safe/ content positive affect before and after CFI $[F(1,38)=6.07, p=$ .018]. The first post hoc test revealed that in the oxytocin condition, individuals with low levels of self-reassurance reported less safe/content positive affect after CFI, [t(38) $=-2.23, p=.031]$, compared with individuals with high self-reassurance. Second, the degree of safe/content positive affect reported by low selfreassured individuals was less after oxytocin and CFI than after placebo and CFI $[t(18)=2.80, p=.012]$.

\section{Social Safeness}

A significant interaction was found between level of social safeness and spray condition in 'ease of receiving compassion' (question 1) $[F(1,39)=9.14, p=.004]$ (see Figure 2). Post hoc tests revealed that in the oxytocin condition those low in social safeness found it more difficult to receive compassion than in the oxytocin condition $[t(17)=-3.72, p=.002]$ compared with those higher in social safeness $[t(39)=-2.34, p=.024]$. In addition, we found a near-significant interaction regarding 'how moved participants felt' by CFI (question 6 ) $[F(1,39)=4.10, p=.050]$. However, post hoc tests did not reveal any significant effects. With regard to changes in positive affect in response to CFI, a significant interaction was found between level of social safeness and safe/content positive affect before and after CFI $[F(1,38)=4.18$,

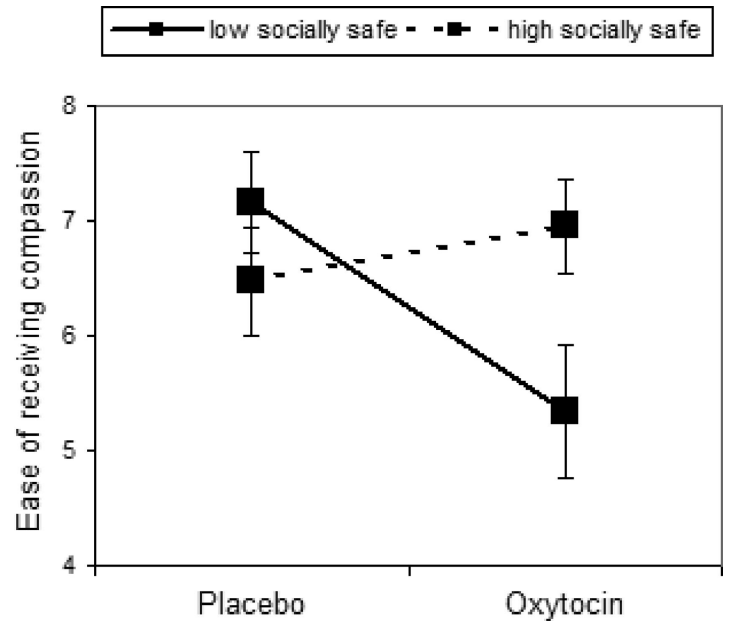

Figure 2. Interaction between spray condition and ability to feel socially safe for self-reported ease of receiving compassionate emotions. $p=.048]$. Post hoc tests revealed that after oxytocin and CFI, the amount of safe/content positive affect reported by low socially safe individuals decreased $[t(22)=2.68, p=.014]$.

\section{Adult Attachment}

We found a significant interaction between 'closeness to others' score and spray condition for 'resistance to the compassionate emotions' (question 2) $[F(1,39)=4.67, p=.039]$. Post hoc tests yielded that those high in closeness to others showed a nonsignificant trend to show less 'resistance to the compassionate emotions' than those low in closeness, in the oxytocin condition $[t(39)=$ $1.94, p=.064]$. They also showed a nonsignificant trend to report lower resistance after oxytocin as compared to placebo $[t(17)=$ $1.92, p=.071]$. In addition, we found an interaction between levels of closeness and 'feeling tense' (question 3) $[F(1,39)=$ $4.72, p=.036]$, but post hoc tests did not reveal significant effects. With regard to changes in positive affect in response to CFI, a significant interaction was found between level of closeness and relaxed positive affect before and after CFI $[F(1,38)=4.29, p=$ .045]. Post hoc tests revealed that individuals low in closeness showed increased relaxed scores with placebo and CFI $[t(22)=$ $-4.39, p<.001]$. There were also increases in relaxed positive affect for individuals with high closeness in the placebo $[t(22)=$ $-4.46, p<.001]$ and oxytocin $[t(22)=-5.27, p<.001]$ conditions. However, after placebo, the levels of relaxed positive affect reported by low closeness individuals were less than those reported by high close individuals $[t(39)=-2.31, p=.021]$. There was a significant interaction between level of anxious attachment and relaxed positive affect before and after CFI $[F(1$, $38)=4.27, p=.046]$. Post hoc tests revealed that in the placebo condition, low anxious individuals increased in relaxed positive affect with CFI $[t(19)=-3.58, p=.002]$, compared with those high in anxious attachment. In addition, high anxious individuals increased in relaxed positive affect in the placebo $[t(20)=-5.48$, $p=.000]$ and oxytocin $[t(20)=-3.96, p=.001]$ conditions.

\section{Gender Differences}

A significant interaction was found between mood before and after CFI and gender for the variable activated positive affect (TPAS) $[F(1,38)=4.52, p=.040]$. A $t$ test revealed a nonsignificant trend for women to show larger decreases in activated positive affect after CFI than men $[t(39)=1.99, p=.054]$. No other significant effects for gender were found.

\section{Discussion}

\section{Effects of Oxytocin on CFI Experience and Mood}

This study tested the hypothesis that intranasal oxytocin will improve the ease of imagining compassion and reduce resistance to the emotional content of the CFI. In accordance with this hypothesis, taking the group as a whole, oxytocin did significantly enhance the ease of imagining receiving compassion from another person/being and receiving various compassionate qualities for the self (question 8). This finding is in line with recent research which identified oxytocin as a facilitator of a range of affiliative emotions and prosocial behaviors (Guastella, Mitchell, \& Mathews, 2008; 
Heinrichs \& Domes, 2008; Kosfeld et al., 2005; MeyerLindenberg, 2008).

In terms of positive affect measured before and after CFI, relaxed positive affect increased and activated positive affect decreased (in both spray conditions). Interestingly, safe/content positive affect did not change. One reason for this may be that this subscale has only four items. In addition, it could be a result of individual differences in responses to CFI with oxytocin. For example, we found that low social safeness and low self-reassured individuals reported a decrease in safe/content positive affect in the oxytocin condition. This could in part account for the null findings for the overall sample with regard to changes in safe/ content positive affect.

\section{Role of Individual Differences in Response to CFI and Oxytocin}

This study revealed important individual differences in the experience of CFI and oxytocin. People with lower selfreassurance and lower feelings of social safeness found it significantly more difficult to receive compassionate emotions (question 1) in the oxytocin condition. This may be consistent with recent findings of Bartz et al. (2010b) that oxytocin makes access to attachment memories easier, but much will depend on how secure ones attachment style is.

Qualitative data further revealed that for a number of the higher self-critical individuals, CFI under oxytocin was associated with a range of unpleasant experiences such as anger and frustration about the inability to generate a compassionate image, sadness about loss, feeling depressed, and describing the experience as 'a bit scary.' Oxytocin may have made them more sensitive to wanting an affiliative experience but also recognizing that they had no close attachment figure and felt lonely_as indicated by three self critical people. Under placebo these individuals reported less aversive responses.

There were some significant effects for facilitation of CFI with oxytocin in the more self-reassuring participants, who found it easier to receive compassionate emotions; those higher in social safeness showed a near significant effect of feeling more moved by their compassionate image (question 6); those higher in closeness were less tense (question 3) and showed a nonsignificant trend to feel less resistance (question 2) to their compassionate image. Finally, those high in closeness were more relaxed with CFI (in both conditions).

In general, increases in positive affect were more pronounced in the placebo condition than the oxytocin condition. This could be attributable to individual differences in how some individuals experienced CFI with oxytocin, as results indicate that low selfreassured individuals and those low in social safeness showed decreases in safe/content positive affect with CFI under oxytocin. Aside from this finding, there were few significant effects of individual differences revealed in the placebo condition. It is possible that under placebo the effects of CFI were too subtle to reach significance in self-report measures. Future work might wish to compare in more detail priming affiliative behaviors with imagery alone in comparison to oxytocin, perhaps using physiological or cognitive measures in addition to self-report to assess more subtle, nonconscious effects.

\section{Role of Gender}

The only gender variation we found was for a trend for women to show a greater decrease in activated positive affect by CFI irrespective of spray condition. Most studies exploring oxytocin used single gender samples (mostly men). There are few studies which include both men and women, and in general these do not reveal gender differences (Guastella et al., 2009a; Shamay-Tsoory et al., 2009; Theodoridou et al., 2009). The number of women in our study was small and therefore future research needs to address the gender issue.

\section{Clinical Implications}

In general our findings suggest that there are important individual differences in experiencing compassion from guided imagery, especially when facilitated through oxytocin. This suggests that the effects of affiliative imagery, such as CFI and LKM, may rely on attachment experiences and memory. Individuals who are self-critical, insecurely attached, and lack a sense of social safeness can find various elements of compassion difficult, especially with oxytocin. These findings are consistent with recent research which found that oxytocin does not have broad positive effects for all recipients, rather the effects of oxytocin appear dependent on individual differences such as attachment style (Bartz et al., 2010b). As previously noted, Bartz et al. (2010b) found that when given oxytocin, less anxiously attached individuals recalled their mother as more close and caring; in contrast, more anxiously attached individuals recalled their mother as less close and caring. These findings are important because oxytocin is widely thought of as having beneficial effects for all recipients and as such has become the focus of therapeutic interventions (Guastella et al., 2009b; Hollander et al., 2007; Hollander et al., 2003). However, this study suggests that whether CFI under oxytocin is experienced as positive or negative depends on one's attachment style and levels of self-criticism. Recent research also indicates that oxytocin is not a general affiliative hormone but can be associated with an increase in envy and gloating (Shamay-Tsoory et al., 2009). Moreover oxytocin might have quite different effects on affiliative emotions toward others according to whether targeted individuals are perceived as in-group members or out-group members (De Dreu et al., 2010; De Dreu, Greer, Van Kleef, Shalvi, \& Handgraaf, 2011).

Our data on self-criticism is interesting because it is known that self-criticism can negatively influence therapeutic outcomes, with self-critics tending to do less well with standard therapies such as cognitive-behavioral therapy (Rector, Bagby, Segal, Joffe \& Levitt, 2000). Studies which have shown beneficial effects of oxytocin in combination with therapy had not controlled for self-criticism (Guastella et al., 2009b; Hollander et al., 2007; Hollander et al., 2003). However, we also note that some researchers have found that compassion practices can be helpful to self-critical people when they are guided through specific types of compassion practices (Gilbert \& Procter, 2006; Laithwaite et al., 2009; Kelly, Zuroff, \& Shapira, 2008; Mayhew \& Gilbert, 2008; Mongrain, Chin, \& Shapira, in press).

Although these findings are promising, future research could focus more on a range of individual differences such as the degree of neglect or abuse in the person's past and degree of experience with mental imagery/meditation. For example, Wismer Fries, Ziegler, Kurlan, Jacorls, and Pollak (2005) found that children who had experienced severe neglect in an orphanage but had been 
adopted into a loving home (average 34.6 months) still showed abnormalities in oxytocin responsiveness during interaction with their caregiver, indicating that perhaps these systems do not recover easily from early neglect.

We also draw attention to the value of gaining in-depth qualitative data. For example, for individuals who have experiences of poor early attachment, activating the attachment/affiliative system could stimulate a sense of grief and yearning for closeness (Gilbert, 2009, 2010). Indeed, one highly self-critical participant was tearful during the CFI, especially with oxytocin. It is also interesting to note that individuals with high self-criticism showed greater resistance to compassionate emotions when given oxytocin first (i.e., before the placebo/CFI session). This could indicate a more difficult experience when introduced to CFI for the first time after oxytocin.

The reasons why individuals can struggle with affiliative emotions are complex, requiring further research (Gilbert et al., in press). For example, although there is good evidence that oxytocin orients individuals to engage in social roles (especially affiliative) in various ways (Lee, Macbeth, Pagani \& Young, 2009; MacDonald \& MacDonald, 2010), if these roles are frightening for some people, then the experience under oxytocin may be aversive. Gilbert (2010) and Gilbert \& Irons, (2005) suggested that if the attachment system has been traumatized or closed down because of neglect or abuse, compassion-focused work or oxytocin may reactivate the attachment and affiliative motivational systems. This opens access to unprocessed emotions or difficult memories (e.g., yearning for closeness or closeness being associated with abuse).

This research has highlighted that, although oxytocin enhances the CFI experience, there are important individual differences in responses to both oxytocin and CFI. There are increasing suggestions that oxytocin may be of use in therapeutic settings because of its effects on social processing, social approach behavior, and affiliative motivation (Guastella et al., 2009b; Hollander et al., 2007; Hollander et al., 2003). Therefore the findings in this study that not all individuals respond the same to oxytocin are of great importance in developing therapeutic interventions, in addition to gaining a deeper understanding of affiliative systems. These differences may provide important insights into key areas of psychopathology, especially those that are linked to resilience and abilities to be self-soothing and to be able to turn to others for support. In addition, these individual differences should be borne in mind when using CFI and/or oxytocin in experimental clinical studies and as a potential adjunct to therapeutic interventions.

\section{References}

Arbuthnott, K. D., Arbuthnott, D. W., \& Rossiter, L. (2001). Guided imagery and memory: Implications for psychotherapists. Journal of Counseling Psychology, 48, 123-132.

Bartz, J. A., Zaki, J., Bolger, N., Hollander, E., Ludwig, N. N., Kolevzon, A., \& Ochsner, K. N. (2010a). Oxytocin selectively improves empathic accuracy. Psychological Science, 21, 1426-1428.

Bartz, J. A., Zaki, J., Oshsner, K. N., Bolger, N., Kolvezon, A., Ludwig, N., \& Lydon, J. E. (2010b). Effects of oxytocin on recollections of maternal care and closeness. Proceedings of the National Academy of Sciences, USA, 107, 21371-21375.

Baumgartner, T., Heinrichs, M., Vonlanthen, A., Fischbacher, U., \& Fehr, E. (2008). Oxytocin shapes the neural circuitry of trust and trust adaptation in humans. Neuron, 58, 639-650.

Bell, D. C. (2001). Evolution of care giving behaviour. Personality and Social Psychology Review, 5, 216-229.
Bowlby, J. (1969). Attachment and loss: Vol. 1. Attachment. New York: Basic Books.

Bowlby, J. (1973). Attachment and loss: Vol. 2. Separation, anxiety and anger. New York: Basic Books.

Buchheim, A., Heinrichs, M., George, C., Pokorny, D., Koops, E., Henningsen, P., . . Gündel, H. (2009). Oxytocin enhances the experience of attachment security. Psychoneuroendocrinology, 34, 1417-1422.

Cacioppo, J. T., Berston, G. G., Sheridanm, J. F., \& McClintock, M. K. (2000). Multilevel integrative analysis of human behavior: Social neuroscience and the complementing nature of social and biological approaches. Psychological Bulletin, 126, 829-843.

Carter, C. S. (1998). Neuroendocrine perspectives on social attachment and love. Psychoneuroendorinlogy, 23, 779-818.

Collins, N. L., \& Read, S. J. (1990). Adult attachment, working models, and relationship quality in dating couples. Journal of Personality and Social Psychology, 58, 644-663.

Cozolino, L. (2007). The neuroscience of human relationships: Attachment and the developing brain. New York: Norton.

Cozolino, L. (2008). The healthy aging brain: Sustaining attachment, attaining wisdom. New York Norton.

De Dreu, C. K. W., Greer, L. L., Handgraaf, M. J. J., Shalvi, S., Van Kleef, G. A., Baas, M., . . Feith, S. W. W. (2010). The neuropeptide oxytocin regulates parochial altruism in intergroup conflict among humans. Science, 328, 1408-1411.

De Dreu, C. K. W., Greer, L. L., Van Kleef, G. A., Shalvi, S., \& Handgraaf, M. J. J. (2011). Oxytocin promotes human ethnocentrism. Proceedings of the National Academy of Sciences, USA, 108, 1262-1266.

Depue, R. A., \& Morrone-Strupinsky, J. V. (2005). A neurobehavioral model of affiliative bonding. Behavioral and Brain Sciences, 28, 313-395.

Domes, G., Heinrichs, M., Glascher, J., Buchel, C., Braus, D. F., \& Herpetz, S. C. (2007a). Oxytocin attenuates amygdala responses to emotional faces regardless of valence. Biological Psychiatry, 62, 1187-1190.

Domes, G., Heinrichs, M., Michel, A., Berger, C., \& Herpetz, S. C. (2007b). Oxytocin improves "mind-reading" in humans. Biological Psychiatry, 61, 731-733.

Fredrickson, B. L., Cohn, M. A., Coffey, K. A., Pek, J., \& Finkel, S. A. (2008). Open hearts build lives: Positive emotions, induced through loving-kindness mediation, build consequential personal resources. Journal of Personality and Social Psychology, 95, 1045-1062.

Gilbert, P. (2000). Social mentalities: Internal "social" conflicts and the role of inner warmth and compassion in cognitive therapy. In P. Gilbert \& K. G. Bailey (Eds.), Genes on the couch: Explorations in evolutionary psychotherapy (pp. 118-150). Hove: Brenner-Routledge.

Gilbert, P. (2009). The compassionate mind. London: Constable-Robinson. Oakland, CA: New Harbinger.

Gilbert, P. (2010). Compassionate mind: A new approach to life's challenges. London: Constable-Robinson. Oakland, CA: New Harbinger.

Gilbert, P., Clarke, M., Hempel, S., Miles, J., \& Irons, C. (2004). Criticising and reassuring oneself: An exploration of forms, styles and reasons in female students. British Journal of Clinical Psychology, 43, 31-50.

Gilbert, P., \& Irons, C. (2005). Focused therapies and compassionate mind training for shame and self-attacking. In P. Gilbert (Ed.), Compassion: Conceptualisations, research and use in psychotherapy (pp. 263-325). London: Routledge.

Gilbert, P., McEwan, K., Bellew, R., Mills, A., \& Gale, C. (2009). The dark side of competition: How competitive behaviour and striving to avoid inferiority are linked to depression, anxiety, stress and self-harm. Psychology and Psychotherapy: Theory, Research and Practice, 82, 123-136.

Gilbert, P., McEwan, K., Matos, M., \& Rivis, A. (in press). Fears of compassion: Development of three self-report measures. Psychology and Psychotherapy.

Gilbert, P., McEwan, K., Mitra, R., Franks, L., Richter, A., \& Rockliff, H. (2008). Feeling safe and content: A specific affect regulation system? 
Relationship to depression, anxiety, stress and self-criticism. Journal of Positive Psychology, 3, 182-191.

Gilbert, P., \& Procter, S. (2006). Compassionate mind training for people with high shame and self-criticism: A pilot study of a group therapy approach. Clinical Psychology and Psychotherapy, 13, 353-379.

Gillath, O., Shaver, P. R., \& Mikulincer, M. (2005). An attachment-theoretical approach to compassion and altruism. In P. Gilbert (Ed.), Compassion: Conceptualisations, research and use in psychotherapy (pp. 121-147). London: Routledge.

Goetz, J. L., Keltner, D., \& Simon-Thomas, E. (2010). Compassion: An evolutionary analysis and empirical review. Psychological Bulletin, 136, 351-374.

Guastella, A. J., Einfeld, S. L., Gray, K. M., Rinehart, N. J., Tonge, B. J., Lambert, T. J., \& Hickie, I. B. (2009a). Intranasal oxytocin improves emotion recognition for youth with autism spectrum disorders. Biological Psychiatry, 67, 692-694.

Guastella, A. J., Howards, A. L., Dadds, M. R., Mitchell, P., \& Carson, D. S. (2009b). A randomized controlled trial of intranasal oxytocin as an adjunct to exposure therapy for social anxiety disorder. Psychoneuroendocrinology, 34, 917-923.

Guastella, A. J., Mitchell, P. B., \& Mathews, F. (2008). Oxytocin enhances the encoding of positive social memories in humans. Biological Psychiatry, 64, 256-258.

Hall, E., Hall, C., Stradling, P., \& Young, D. (2006). Guided imagery: Creative interventions in counselling and psychotherapy. London: Sage.

Heinrichs, M., Baumgartner, T., Kirschbaum, C., \& Ehlert, U. (2003). Social support and oxytocin interact to suppress cortisol and subjective responses to psychosocial stress. Biological Psychiatry, 54, 1389-1398.

Heinrichs, M., \& Domes, G. (2008). Neuropeptides and social behaviour: Effects of oxytocin and vasopressin in humans. Progress in Brain Research, 170, 337-350.

Hollander, E., Bartz, J., Chaplin, W., Phillips, A., Sumner, J., Sooyra, L., . . . Wasserman, S. (2007). Oxytocin increases retention of social cognition in autism. Biological Psychiatry, 61, 498-503.

Hollander, E., Novotny, S., Hanratty, M., Yaffe, R., DeCaria, C. M., Aronowitz, B. R., \& Mosovich, S. (2003). Oxytocin infusion reduces repetitive behaviours in adults with autistic and aspergers disorders. Neuropsychopharmacology, 28, 193-198.

Holmes, E. A., \& Mathews, A. (2010). Mental imagery in emotion and emotional disorders, Clinical Psychology Review, 30, 349-362.

Insel, T. R. (1997). A neurobiological basis of social attachment. American Journal of Psychiatry, 154, 726-735.

Kelly, A. C., Zuroff, D. C., \& Shapira, L. B. (2008). Soothing oneself and resisting self-attacks: The treatment of two interpersonal deficits in depression vulnerability. Cognitive Therapy and Research, 33, 301-313.

Kirsch, P., Esslinger, C., Chen, Q., Mier, D., Lis, S., Siddanti, S., . . MeyerLindenberg, A. (2005). Oxytocin modulates neural circuitry for social cognition and fear in humans. The Journal of Neuroscience, 25, 1148911493.

Kosfeld, M., Heinrichs, M., Zak, P. J., Fischbacher, U. \& Fehr, E. (2005). Oxytocin increases trust in humans. Nature, 435, 673-676.

Laithwaite, H., O'Hanlon, M., Collins, P., Doyle, P., Abraham, L., Porter, S., \& Gumley, A. (2009). Recovery After Psychosis (RAP): A compassion focused programme for individuals residing in high security settings. Behavioural and Cognitive Psychotherapy, 37, 511-526.

Lee, H. J., Macbeth, A. H., Pagani, J. H., \& Young, W. S. (2009). Oxytocin: The great facilitator of life. Progress in Neurobiology, 88, 127-151.
Longe, O., Maratos, F. A., Gilbert, P., Evans, G., Volker, F., \& Rockliff, H., \& Rippon, G. (2010). Having a word with yourself: Neural correlates of self-criticism and self-reassurance. NeuroImage, 49, 1849-1856.

Luyten, P., Sabbe, B., Blatt, S. J., Meganck, S., Jansen, B., Grave, C., ... Correleyn, J. (2006). Dependency and self-criticism: Relationship with major depressive disorder, severity of depression, and clinical presentation. Depression and Anxiety, 24, 586-596.

MacDonald, K., \& MacDonald, T. M. (2010). The peptide that binds: A systematic review of oxytocin and its prosocial effects in humans. Harvard Review of Psychiatry, 18, 1-21.

Mayhew, S., \& Gilbert, P. (2008). Compassionate mind training with people who hear malevolent voices: A case series report. Clinical Psychology and Psychotherapy, 15, 113-138.

Meyer-Lindenberg, A. (2008). Impact of prosocial neuropeptides on human brain function. Progress in Brain Research, 17, 463-470.

Mikulincer, M., \& Shaver, P. R. (2007). Attachment in adulthood: Structure, dynamics, and change. New York: Guilford Press.

Mongrain, M., Chin, J. M., \& Shapira, L. B. (in press). Practicing compassion increases happiness and self-esteem. Journal of Happiness Studies.

Panksepp, J. (1998). Affective neuroscience. New York: Oxford University Press.

Petrovic, P., Kalisch, R., Singer, T., \& Dolan, R. J. (2008). Oxytocin attenuates affective evaluations of conditioned faces and amygdala activity. Journal of Neuroscience, 28, 6607-6615.

Porges, S. W. (2007). The polyvagal perspective. Biological Psychology, 74, $116-143$.

Rector, N. A., Bagby, R. M., Segal, Z. V., Joffe, R. T., \& Levitt, A. (2000)., Self-criticism and dependency in depressed patients treated with cognitive therapy or pharmacotherapy. Cognitive Therapy \& Research, 24, 571-584.

Rimmele, U., Hediger, K., Heinrichs, M., \& Klaver, P. (2009). Oxytocin makes a face in memory familiar. Journal of Neuroscience, 29, 38-42.

Rockliff, H., Gilbert, P., McEwan, K., Lightman, S., \& Glover, D. (2008). A pilot exploration of heart rate variability and salivary cortisol responses to compassion-focused imagery. Journal of Clinical Neuropsychiatry, 5, 132 139.

Savaskan, E., Ehrhardt, R., Schulz, A., Walter, M., \& Schachinger, H. (2008). Post-learning intranasal oxytocin modulates human memory for facial identity. Psychoneuroendocrinology, 33, 368-364.

Shamay-Tsoory, S. G., Fischer, M., Dvash, J., Harari, H., Perach-Bloom, N., \& Levkovitz, Y. (2009). Intranasal administration of oxytocin increases envy and schadenfreude (gloating). Biological Psychiatry, 66, 864-870.

Stopa, L. (2009). Imagery and the threatened self: Perspective on mental imagery and the self in cognitive therapy. London: Routledge.

Theodoridou, A., Rowe, A. C., Penton-Voak, I. S., \& Rogers, P. J. (2009). Oxytocin and social perception: Oxytocin increases perceived facial trustworthiness and attractiveness. Hormones and Behaviour, 56, 128-132.

Watson, D., Clark, L. A., \& Tellegen, A. (1988). Development and validation of brief measures of positive and negative affect: The PANAS scales. Journal of Personality and Social Psychology, 54, 1063-1070.

Whelton, W. J., \& Greenberg, L. S. (2005). Emotion in self-criticism. Per sonality and Individual Differences, 38, 1583-1595.

Wismer Fries, A. B., Ziegler, T. E., Kurlan, J. R., Jacorls, S., \& Pollak, S. D. (2005). Early experience in humans is associated with changes in neuropeptides critical for regulating social behaviour. Proceedings of the National Academy of Sciences, USA, 102, 17237-17240.

Zuroff, D. C. (1992). New directions for cognitive models of depression. Psychological Inquiry, 3, 274-277. 


\section{Appendix 1}

\section{After Imagery Questions for Oxytocin Study}

Now that you have tried doing some compassionate imagery we are interested to know of how you found it. People respond in many different ways to this kind of imagery work, so please remember there are no right or wrong answers. This is exploratory research, so we are not looking for anything particular. We are interested in the answers that are true for you based on your experiences just now.

1) How easy did you find it to experience receiving the compassionate emotions?

$\begin{array}{rrrrrrrrr}1 & 2 & 3 & 4 & 5 & 6 & 7 & 8 & 9 \\ \text { Very Easy } & & & & & & & & 10 \\ \text { Difficult }\end{array}$

2) Was there a part of you that wanted to resist feeling the compassionate emotions?

$\begin{array}{llllllllll}1 & 2 & 3 & 4 & 5 & 6 & 7 & 8 & 9 & 10\end{array}$ Did Not Strongly Want to Resist Wanted to Resist

3) How tense do you feel at the moment?

$\begin{array}{lllllllllll}1 & 2 & 3 & 4 & 5 & 6 & 7 & 8 & 9 & 10\end{array}$ Not Tense at All Very Tense

4) How hard did you try to create a visual image for the compassionate emotions to come from?

$\begin{array}{lllllllllll}1 & 2 & 3 & 4 & 5 & 6 & 7 & 8 & 9 & 10\end{array}$ Did Not Try Tried Hard

5) How clearly could you see your image?

$\begin{array}{lccccccccc}1 & 2 & 3 & 4 & 5 & 6 & 7 & 8 & 9 & 10 \\ \text { No Image } & & & & & & \text { Clear as a Photo }\end{array}$

6) How moved did you feel by the presence of these compassionate emotions for you?

$\begin{array}{lllllllllll}1 & 2 & 3 & 4 & 5 & 6 & 7 & 8 & 9 & 10\end{array}$

Not Moved Very Moved

7) Did you feel any sadness in response to trying this compassionate imagery?

$\begin{array}{llllllllll}1 & 2 & 3 & 4 & 5 & 6 & 7 & 8 & 9 & 10\end{array}$ Felt No Sadness Felt Overwhelmed by Sadness

8) How easy was it for you to feel your compassionate image (or other mind) having the following...

\footnotetext{
Wisdom

$\begin{array}{llllllllll}1 & 2 & 3 & 4 & 5 & 6 & 7 & 8 & 9 & 10\end{array}$
}

\section{Strength}

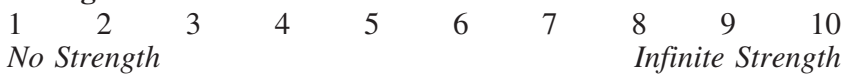

Dependability

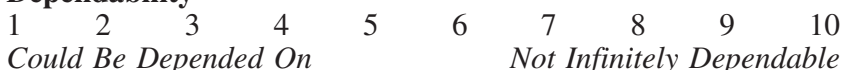

Non-Judgment

$\begin{array}{llllllllll}1 & 2 & 3 & 4 & 5 & 6 & 7 & 8 & 9 & 10\end{array}$

Very Judgmental Non-Judgmental

\section{Kindness}

$\begin{array}{rrrrrrrrrr}1 & 2 & 3 & 4 & 5 & 6 & 7 & 8 & 9 & 10\end{array}$

Not Kind Very Kind

Warmth

$\begin{array}{cccccccccc}1 & 2 & 3 & 4 & 5 & 6 & 7 & 8 & 9 & 10 \\ \text { Not Warm } & & & & & & & \text { Very Warm }\end{array}$

Care

$\begin{array}{llllllllll}1 & 2 & 3 & 4 & 5 & 6 & 7 & 8 & 9 & 10\end{array}$

No Care Very Caring

Understanding

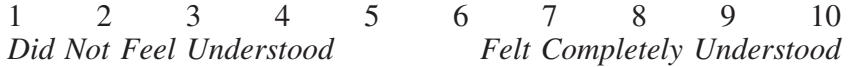

9) What was your compassionate image? (if you didn't have any image please put N/A, and if you only had bits of hazy imagery just note down what these were like as best you can).

10) We are interested to know how you personally found this experience. If there is anything you felt or thought during the imagery that we haven't asked you about please write it below. You can also use this space to give us more general feedback on your experience if you wish to (e.g. things you found difficult or tips that you discovered for helping you feel compassion).
Received August 9, 2010

Revision received March 3, 2011

Accepted March 10, 2011 